\title{
Primary Student Teachers' Understanding of Mathematics and its Teaching
}

British Educational Research Journal, 1999, 25(3), 299-323

TONY BROWN The Manchester Metropolitan University

OLWEN MCNAMARA The Manchester Metropolitan University

UNA HANLEY The Manchester Metropolitan University

LIZ JONES The Manchester Metropolitan University

\begin{abstract}
This paper reports on research into primary student teachers' understanding of mathematics and its teaching undertaken at the Manchester Metropolitan University and funded by the Economic and Social Research Council. The research set out to investigate the ways in which non-specialist student teachers conceptualise mathematics and its teaching and how their views evolve as they progress through an initial training course. The study has shown how the mathematical understanding of such students is, in the first instance, embedded in a strongly affective account of their own mathematical experiences in schools, where mathematics was often seen as difficult and threatening. College training successfully nurtures a more positive attitude to mathematics as a subject, albeit couched in a pedagogically oriented frame. In later stages of training however, their conceptions of mathematics and its teaching are subsumed within the organisational concerns of placement schools and school experience tutors, and shaped by commercial schemes. It is suggested that alternative conceptions of mathematics assumed at different stages of this training appear incommensurable. A theoretical framework is offered as an approach to reconciling this conflict. This demonstrates how three potential dichotomies, phenomenological/ official versions of mathematics, discovery/ transmission conceptions of mathematics teaching, perceptual/ structural understandings of the mathematics teacher's task can be seen as productive dualities harnessing both qualitative and quantitative perspectives.
\end{abstract}

\section{Introduction}

In recent years the drive to improve the educational standards in English schools has become a high profile national issue. The training of teachers has come under scrutiny with a number of radical reforms already in place and others planned (DfEE, 1997, 1998; CATE, 1992). Mathematics teaching in particular has become the focus of attention as evidence continues to emerge of the ostensibly declining mathematical performance of English pupils viewed in a comparative international context (SIMS, 1990; TIMSS, 1996). Policy shifts arising from this debate include the ongoing revision of the National Curriculum and the impending introduction of the National Numeracy Strategy that will be implemented in 1999 by a primary teaching force disparate in both their interpretations of mathematics and their ideas regarding effective intervention strategies. Initial Teacher Education (ITE), if it is to be successful, must prepare the student to become an effective operator within this complex political and educational context.

This paper reports on a one year long ESRC funded study the aims of which were to: (1) develop an empirically informed theoretical account of how school mathematics and its teaching is constructed by the non-mathematics specialist primary BEd students as they effect the transition from learner of mathematics to teachers of mathematics; (2) document the cognitive and affective elements of the understandings of mathematics that students bring with them into 
ITE and the nature of the transition of these conceptions through their college life; (3) explore how the student teacher as learner negotiates a position within the complex school/college partnership involving as it does initiation into multiple facets of mathematics and good practice; and (4) explore how the ITE course could better enable students to critically engage in the transitional process which embodies their professional induction.

Our conjecture was that the student experiences the transitional process, embracing multiple and shifting conceptions of teaching and mathematics, as complex and disjointed. Adopting the identity of student teacher necessitates the playing of many different roles which are enacted within a school/college/government partnership that is itself complex and evolving; learner, pedagogue, assessor, college representative, school employee, carer etc. (Morgan, 1997). Novices ingest this sometimes uneasy alliance into their own developing professional sense and, as a consequence, inevitably find themselves being drawn in a number of directions according to the diverse motivations and demands of the contributing agencies. Many competing agendas can be seen to be in operation. Official accounts of England's relatively poor mathematical performance, for example, attribute it to prevailing 'progressive' primary pedagogies in which too much emphasis is placed on differentiated work and too little on whole class teaching (Reynolds \& Farrell, 1996). Recent government policy responses to such concerns, however, have resulted in greater emphasis being placed on school-based initial training of teachers, thus privileging 'performativity' and affirming classroom competence as the benchmark of accomplishment. Yet, ironically, such a move has placed student teachers in the very site where styles of practice and standards of performance are seen as a particular problem.

\section{What do we know about how student teachers learn?}

Many descriptions of, and prescriptions for, pre-service teachers have presented a unilateral account of the complex teaching situation, furnishing perhaps an overly rational and socially disembodied model. A phenomenological strand of studies has charted students' developing images of classroom practice (Calderhead \& Robson, 1991; Su, 1992; Kyriacou, 1993; Strauss, 1993; Thompson, 1984) or subject matter knowledge (Carter et al., 1993; Carre \& Ernest, 1993; Peterson et al., 1989; Ball, 1990, 1991). A growing body of literature, triggered partly by the developing role of mentoring, is beginning to look at the affective dimension of the student experience (Boydell, 1994; Maynard \& Furlong, 1993; Elliott \& Calderhead, 1993; Vonk, 1993; Jaworski \& Watson, 1994). Official reports (e.g. HMI, 1991), meanwhile, have concentrated on the development of professional skills and competencies: knowledge about subjects, pedagogy, assessment and learning.

In a more sociological strand of studies, models of teacher education developed to describe the student experience have included "rite of passage" (White, 1989), "apprenticeship of observation" (Lortie, 1975), development of expertise (Berliner, 1988), and "induction of novices by experts into culturally based understandings and skills" (Edwards, 1995). Lave and Wenger's (1991) analytical perspective on induction, "legitimate peripheral participation", sees learning resulting from asymmetric co-participation within a community of practice where development of expertise and understanding is situationally and contextually grounded. Learning in this model is not "from talk" but "to talk"; the master/apprentice relation, where it exists, functions to confer legitimacy rather than to provide teaching. The significance of the "social milieu created by the 
rite of passage" (Eisenhart et al., 1991 p. 67) is highlighted in a number of models where it is seen to be the dominant concern of the student and includes a highly affective dimension (McNally et al., 1994; Applegate, 1987; Tickle, 1994). Comfort in personal relations with staff and pupils is often invoked by students as evidence of their final transition to teacher status (McNally et al., 1994; Guillaume \& Rudney, 1993). Tensions inherent in such models are explored by Eisenhart et al. (1991) who found that no one theory was consistently applicable in their education programme, which appeared to send out confused messages to the students. A potential hazard of the current partnership "model" of ITE is that it inevitably presents students with situated learning contexts which are not only diverse but also have potentially disparate, if not overtly conflicting, discourses and agendas.

With regard to mathematics teacher education, Eisenhart et al. (1991, p. 51) found "no systematic body of knowledge about the relationship between good teaching and [mathematics] teacher education"; they conclude that anecdotal accounts, not informed by explanatory theoretical frameworks, are largely responsible for such incoherence. More generally in mathematics education research, Brown et al. (1990) blame a strong analytic tradition for the fact that even "ethnographic type strategies have tended to be more piecemeal than holistic in their efforts to understand the culture and evaluation of its beliefs" (ibid. p. 652). Macleod (1992) argues in similar vein that the integration of affective and cognitive perspectives and the use of a mixture of quantitative and qualitative methods would strengthen research into mathematics education. In particular he suggests that more attention should be paid to theory building. This seems commensurate with recent theoretical work in which cognitively oriented studies have been castigated for neglecting to account for the social dimension of the individual learner (e.g. Cobb, 1994).

The transition from mathematics scholar to mathematics authority, the complex process of learning to teach, develops as a subtle interplay of the parts to the whole. For the aspiring primary teacher one such part is the initial transition from school learner of mathematics to student teacher of mathematics. This transition if it is to be successful must, for many, involve a considerable degree of 'unlearning' and discarding of mathematical baggage, both in terms of subject misconceptions and attitude problems. Lack of attention to this potential impediment, "may help to account for why teacher education is often such a weak intervention - why teachers (...) are most likely to teach math just as they were taught" (Ball, 1988 p. 40). Certainly there is compelling evidence to suggest that experiences as a learner of mathematics, conceptions about the nature of mathematics and instructional practices as a teacher of mathematics are all profoundly interconnected (Thompson, 1984; Lerman, 1986, 1990; Lampert, 1988; Meredith, 1993). More generally, many would agree that the influences of "pre-program beliefs" and "culturally based filters" (Hollingsworth, 1988), employed as interpretative frameworks to make sense of classroom contexts, must be made explicit and challenged (Bird et al., 1993). Some, however, believe such frameworks are fixed before training (Tabachnick \& Zeichner, 1986). Primary BEd students $(n=12)$ were found to hold images of teaching formed from their own school days which were highly influential in moulding their classroom practice and consequently interacting with other forms of knowledge (Calderhead \& Robson, 1991). Su (1992) in a study $(n=29)$ of training establishments found the teaching experience and the co-operating teachers of greatest influence followed by school pupils and other teachers; course curriculum less so and prior socialisation, family and friends only of mild influence. Bramald et al. (1995), however, 
argue that the effect of training courses $(n=162)$ is not constant and belief systems are not as resistant to change as some research suggests.

Another vital component in the transition 'doer to teacher' is enacted in the transformation of subject knowledge into 'pedagogic content knowledge' (PCK). This repackaging of mathematics necessitates facility with the representations, illustrations, examples, explanations and analogies which make mathematical ideas comprehensible to others (Shulman, 1986). 'Content' and 'pedagogic content knowledge' are two of Shulman's seven widely acknowledged categories of teacher knowledge (1987, p. 8). The notion that development of PCK is the most important and difficult element of learning to be an effective teacher is currently popular both in Britain and America (Brown \& Borko, 1992; McDiarmid et al., 1989; Grossman et al., 1989). New teachers, particularly in primary education, have been observed to lack versatility in this pivotal competence (eg. DES, 1988; Alexander et al., 1992).

Critics (e.g. Meredith, 1993; McNamara, 1991; Stones, 1992), however, believe that the framework is not sufficiently dynamic to allow for a non-absolutist view of mathematics, that it is decontextualised and that it assumes a simple didactic and transmission view of teaching. McNamara (1991) questions whether the distinction 'subject'/ 'pedagogic knowledge' can and should be made at all and observes that subject matter itself is a form of representation. Others stress that PCK is situationally and experientially based grounded in classroom experience (Carter, 1990; Lave \& Wenger, 1991). Aubrey (1993, 1994, 1995, 1996) explored this notion in a study of children's informal mathematical knowledge; teachers' subject/ curriculum knowledge, values and beliefs; and, classroom practice (exemplifying, in her view, PCK).

Carter et al. (1993), as part of a follow-up survey to the Leverhulme Primary Project (Wragg et al., 1989), found that the change in content knowledge and substantive knowledge of mathematics of PGCE student teachers $(n=59)$ during training was not significant. They expressed concern that an increasingly school based training would cause the situation to deteriorate further (Carre \& Ernest, 1993). Meredith (1993) in a study of 12 students taken from across 3 different courses concluded that students' PCK was not robustly connected to their training. Rather, she concluded, differences in attitudes might be due to prior learning, knowledge, experience, values and epistemological beliefs. The acquisition of pedagogic content knowledge", she suggested, was related to the "transformation of subject knowledge which results from thinking about subject matter and learning in relation to teaching tasks" (1993, p. 336). The situational nature of teachers' reasoning about classroom tasks was the focus of research by Simon and Brown (1996, p. 7) who found that "gaps in subject knowledge undermine the common rationalisation of teacher's authority in the classroom, that it is necessary to be an authority and in authority".

\section{Research Design}

\section{Collection of data.}

The study was carried out over the course of one academic year at the Didsbury School of Education where the BEd (Primary) programme draws an annual intake of some 200 students and provides an exemplar of advanced partnership arrangements having consistently achieved the 
highest OFSTED rating. Complete data sets were achieved for 20 students ( 5 from each of the 4 years of the course). An initial sample of $7 / 8$ students per year had been selected and matched for school mathematics performance, sex and age, to facilitate longitudinal comparison. The study took the form of a collaborative inquiry between researcher and student generating narrative accounts within the student's evolving understanding of mathematics and pedagogy in the context of their past, present and future lives. Various sources of data provided "weak" triangulation and background information including classroom observation, observation of college sessions, college tutor and classroom teachers' written and oral reflections. The emphasis throughout the study was on the phenomenological experience of the student, and from thence to a theoretical framework.

Each student was given a semi-structured interview three times during the course of the project. The first interview traced the student's mathematical history and their beliefs about mathematics; their college/school experiences (where appropriate); and, their perceptions of their future task as teachers of mathematics. The second interview was conducted whilst the students were on school experience and was combined with a lesson observation. It pursued the central theme of how the students understood mathematics but sought to ground the discussion in the actuality of, and intentions for, the classroom activity including the mathematical concepts and understandings inherent in it and its positioning within the broader contexts of National Curriculum and school mathematics policy. In addition the students' awareness of the pupils was explored together with their response to the assistance offered by school and college staff involved in supervision.

The final extended interview elicited the students' perceptions of the changes that had occurred over the year in terms of knowledge and attitudes. This sought to integrate a reflective dimension into the interview process whereby students were provided with copies of the transcripts of their first interview prior to the meeting and interviewer and student explicitly referred back to earlier discussions as benchmarks in developing issues. In addition each student was asked to provide recent examples of writing which documented significant events relating to mathematics such as subject knowledge, pedagogy, and perceptions of the course. These pieces of writing not only acted as an aide-mémoire to the student and researcher during this interview but also facilitated discussion on the role of reflective writing in the training process. The specific concerns addressed in this interview included: students' perceptions of the role of reflective writing; the contributions made by school experience/college sessions to their developing professional sense; and, the structures of mathematics as demonstrated by their ability to provide an account of connections between substantive areas they had encountered in their teaching. This interview was piloted beforehand with students who had participated in earlier interviews but had been dropped from the main sample.

The interviews were carried out by all four team members who met regularly in order to: design, trial and finalise interview formats; discuss interpretations of data collected; decide coding strategies; and, formulate provisional conjectures. All such group meetings were minuted to record suggestions as they arose. A number of interviews were observed by a second team member to facilitate discussions concerning the consistency of interview strategies and interpretations. The team's experience encompassed mathematics teaching across all phases, advisory and in-service work as well as ITE. The reconciliation of alternative perspectives this offered facilitated discussion concerning the interpretation of data and progressive focusing on emergent themes (cf. Miles and Huberman, 1984, pp.73-77; Glaser, 1978). 


\section{Analysis of data}

Information was sifted as it was collected and both explicit and implicit categories identified. As this process continued a list of conjectures was drawn up and successively modified as more data was forthcoming. This on-going process informed the construction of later interviews and the honing of intentions. The third interview was expressly devised to build upon earlier analysis; the transcript from the first interview having been sent to the students in advance. This enabled not only transitional issues to be addressed explicitly but also checks to be made with students about interpretations of their earlier statements and the preliminary conjectures ('member checks', Lincoln and Guba, 1985). When it seemed that the final set of categories had emerged the three interview transcripts for each student were trawled in order to identify relevant content and this was then combined to create a synopsis for each student. The entire process placed emphasis on the students' oral and written accounts at successive stages of the course and their own understanding of how change had taken place and how this was manifest in their discussion, writing and teaching. In this way accounts were built of the phenomenological environment in which students operated and how they structured this and were structured by this. Particular attention was paid to the way students, in conceptualising their academic and professional tasks, depicted the relation between college and school practices.

\section{Empirical results}

Initial analysis identified three phases in the student's developmental experience: as pupil at school; as college-based student; and, as school-based student. The first major transition in the process that transforms the mathematics scholar into a mathematics authority is the move from school pupil to college student. Thereafter the identity of the student teacher is constructed in two arenas: college sessions and school placements. The model is not presented as strictly linear although the nature of the BEd course is premised upon a certain amount of 'front-loading' of college sessions in the first 5 terms of the course and back loading of 3 of the 4 school experience practices. Despite this structure there is nevertheless a certain amount of interweaving of collegebased maths sessions and school experience periods. This inevitably introduces the possibility of conflicting agendas between school and college and a number of dilemmas become apparent at the boundary of the two. [Recent course revision will result in current first and second year students receiving additional mathematics training during their third and fourth year].

\begin{tabular}{|l|l|l|l|}
\hline Experience as a pupil & College experience & Boundary dilemmas & School experience \\
\hline Maths Intimidates & $\begin{array}{l}\text { College reduces fear } \\
\text { of maths and failure }\end{array}$ & $\begin{array}{l}\text { 'Ideal' notions of maths } \\
\text { education are challenged in } \\
\text { the 'real world' of the } \\
\text { classroom }\end{array}$ & $\begin{array}{l}\text { Maths is subsumed } \\
\text { by the pragmatics of } \\
\text { pedagogic concerns }\end{array}$ \\
\hline & $\begin{array}{l}\text { College relocates } \\
\text { mathematics and } \\
\text { repositions the } \\
\text { student }\end{array}$ & $\begin{array}{l}\text { Students fantasise/ desire } \\
\text { recipe knowledge rather } \\
\text { than repertoire skills }\end{array}$ & $\begin{array}{l}\text { School experience } \\
\text { tutor and class } \\
\text { teacher input is } \\
\text { primarily pedagogic }\end{array}$ \\
\hline
\end{tabular}




\begin{tabular}{|l|l|l|}
\hline & $\begin{array}{l}\text { College maths is not } \\
\text { targeted effectively to } \\
\text { address practical teaching } \\
\text { issues when most needed }\end{array}$ \\
\hline \multicolumn{2}{|l|}{ Experience as a pupil informs the student's ideal model for teaching } \\
\hline
\end{tabular}

\section{Mathematical experience as a pupil}

1. School mathematics intimidates

"It was horrific" (Yr. 2). "Hate hate hate" (Yr. 1). When feelings about mathematics were explored intense emotions were often exposed. The study cohorts' experience of mathematics at school had been overwhelmingly negative; overall approximately $80 \%$ of the students disliked mathematics or found it a struggle. The one student in the first year cohort who did claim to enjoy maths, linked the pleasure to extrinsic reward: "I like mucking about with figures I got enjoyment when I got it right" (Yr. 1). Another student, in declaring "I'm not frightened by maths" (Yr. 2), both denied and acknowledged its potential to intimidate. Into yet another retrospective account a 'victory narrative' (Stronach \& Maclure, 1997) can be read: "It scares me - I just hated it - my greatest achievement was doing maths" (Yr. 1). If victory there was, however, it was often not attributable to themselves: "I just worked really hard at the end and I was really surprised to get a B, I was predicted a C... it was probably a fluke" (Yr. 3). Most students, however, in recalling encounters with mathematics remembered just the struggle: "even though I got a decent grade at GCSE I found it very very hard... I thought I can't do these in the exam, so I just sat at home and worked and worked" (Yr. 2).

A sense of bafflement about the purpose of school mathematics permeated many accounts leading yet again to a privileging of the 'answer' over the mathematical processes involved. As one student observed: "it's just lots of numbers that didn't make sense... you didn't know what you were doing you just knew if you got it right" (Yr. 3). Retrospective 'it was alright until...' accounts often identified moments when things first started going wrong; stumbling blocks such as 'algebra', 'fractions' and 'secondary school' were identified as pivotal.

A significant number of stories about mathematics were laced with accounts of its construction of self: "I just remember not liking it, being weak, and being a bit of a failure at maths" (Yr. 2). At times its construction of the 'self' was read against its construction of the 'other': "I have to work and work and work at it - there's other people who naturally it would just click for" (Yr. 3); "I never enjoyed maths... you're struggling and the girl next to you is whizzing away" (Yr. 3).

Often present in the students' narratives was the spectre of "the beast of a teacher [who] used to scare us all" (Yr. 1). Traumatic accounts of ritualised humiliation enacted in the classroom were related: "we had to stand up if you didn't get it against the clock and if you didn't get it in 30 seconds you had to stand on a chair and if you didn't get it again you had to stand on the table and if you didn't get it again you had a slap across the legs and made you late home for tea... it's stayed with me all of these years even now I don't think I will ever forget it" (Yr. 4). Where attributes of mathematics teachers were valorised it was for characteristics such as 'approachability', 'patience' and 'humour'. They were identified as teachers who 'really knew us' and used to 'explain things time and time again': "He was funny and he made maths fun and he was kind and took time with us" (Yr. 1). 


\section{Mathematical experience at college}

\section{(1) College sessions reduce fear of mathematics and failure}

The majority of the study cohort was recent school leavers and the emotional baggage that attended their mathematical experiences was still lodged in recent memory. The first year student who liked 'mucking about with figures' felt compelled not to voice such feelings when she first met her fellow students: "I had my first maths core lecture yesterday, they were all going 'its horrible, it's boring'- I wanted to say 'it's not that bad'” (Yr. 1).

Interview data suggested that 'ghosts from the past' were exorcised relatively soon after embarking upon the course. Second year students were no longer reluctant to admit that mathematics wasn't 'that bad': "since I came to Didsbury I just so much enjoy maths" (Yr. 2). The transformation was often quite vividly recalled even years later: "I actually thought hey this is maths I'm coming out and I've actually learnt something and I feel OK about it and I feel quite upbeat about it" (Yr. 4); "we saw maths on the timetable none of us was particularly happy, we all felt quite threatened by it, but we were made to feel at ease because we were given fun activities to do" (Yr. 4). Analysing the change process students observed: "we've unpicked a lot of things on this course and it's made me think that maths isn't just scary numbers" (Yr. 2); "college sessions made me feel good about myself, it made me feel able to do these maths... loads of people, mature students as well, dreaded the maths lesson" (Yr. 4); "it's totally different to anything I've ever experienced at school... they say OK that's great, you're doing fine you have nothing to worry about you're alright with maths" (Yr. 4).

One particular way in which college maths sessions did reduce fear of failure was in reducing the students' focus on 'getting the right answer'. The majority of students upon entering the course held a deep-rooted belief in the privileging of 'answers' over mathematical processes. Given the previous significance of the 'right answer' as often the only tangible product of, and rationale for, engaging in school mathematics it is perhaps not surprising that the apparent inversion of that binary should be so commonly remarked upon. One student observed "it was enjoyable because there wasn't the impact that you had to get everything dead right" (Yr. 3); and another, "it doesn't matter if you don't get the answer as long as you can understand the process and eventually you will come to the answer" (Yr. 3). The message emerging from college was perceived to be "maths should not necessarily be about getting things right it's about the way you work out maths" (Yr. 4). Whilst most students reacted positively to this new model one reflected sadly upon missing "the ticks on the page" and the "that's good, well done!" (Yr. 2).

\section{(2) College sessions reposition the student and relocate mathematics}

Students' conceptions of mathematics inevitably started, and sometimes finished, with 'number' together with a version of 'everyday life' which ranged from 'bus fares' through 'cooking' and 'shopping' to 'finance'. Discreet areas of mathematics often mentioned were 'equations', 'algebra' and 'fractions'. There was a slight observable increase in the sophistication of responses from year 1 to year 4; National Curriculum language such as 'shape and space' began to permeate accounts along with terms such as 'exploring', 'investigating' and 'logic and progression'.

A broadly held view of students entering college was that mathematical ability was innate: "I think you have to have a very mathematical, practical brain. I'm a very arty person... if 
you sat there and learnt and learnt and learnt I still don't think you could change the way you are. I don't think you can suddenly become a mathematical sort of person" (Yr. 1). There was a perception that "some people are good at maths and they just know how to do it" (Yr. 3) and "some people can't get their heads round it" (Yr. 2).

Shifts into a 'can-do' mind-set were, however, evident in a number of accounts: "I thought that's cool I can do that" (Yr. 2); "it was just an amazing feeling to think well it is accessible to me and I can do it" (Yr. 4); "in lessons at college we would sit down and we would all put forward different ways of working it out that enlightened us all" (Yr. 4). A determination to achieve mastery and control of mathematics was apparent: "I go away and do two hours work to try and build up my skills and weave them round it... I've got a different state of mind about maths now than I did before... it was all quite complicated, very intense, difficult, hard" (Yr. 2); "my past is in my brain so I try to forget about my past, about the bad experiences, and I'm trying to start again with maths in the way in which the lecturers have put it across to me" (Yr. 2).

There was even a physical relocation of mathematics in the minds of many student teachers: "before maths was on the board and now it's actually working with blocks, things like that and as a prospective teacher I do find that more interesting and enjoyable" (Yr. 2); "I see it as practical now because they are not just sat down working through pages and pages" (Yr. 4).

Students' shifting perspective during the different phases of the course provided a catalyst for change and offered the potential for empowerment. As one student observed: "It doesn't scare me as much as it did last time because I am seeing it from a different perspective as the teacher, I have the control to make this lesson as good or as bad as it can be" (Yr. 1). Early attempts at taking on the mantle of the teacher presented a one student with a contradiction, however, when read against a college methodology that she felt positioned her as a pupil: "sometimes they will treat us like children put us in the child's place teaching us and giving feedback... but that is completely different because we are adults and they are children I really don't think on their level I thought that was the whole point of being here" (Yr. 2). Incoherence in the structure of the course was also identified by another student: "in all our maths lessons we are always the pupils. You don't do a lot in college about being the teacher. The only time we are the teacher is when we are presenting our ideas from the front" (Yr. 2). These dilemmas were characteristic of those experienced by many students in reconciling messages given in college sessions with possible models for their own practice.

\section{Boundary Dilemmas}

(1) Ideal notions of mathematics education are challenged in the real world of the classroom

The space between college sessions and school experience could be characterised by the dichotomy between the ideal and the real. The tensions were illustrated graphically by one first year student who translated an academic debate about group work into the context of her own child's education: "the disadvantage of group work is that my little boy might be getting kept behind because of the other children he is working with, but I don't tend to worry about that because he is a bright boy" (Yr. 1).

The most common set of dilemmas centred upon 'college methodology': "I don't think I could teach the same way as I was teaching today for one thing it's too intensive" (Yr. 1); "[college] is very much a child-centred approach... and it's OK in theory but once you get into a classroom and you have got 30 children... It's hard saying that you are not going to teach them a 
method... if I tell them to explore they may not get a basic grounding" (Yr. 3). The credibility of 'college maths' was also brought into question by one student: "I think college maths is helpful and appropriate but the teachers sometimes think it looks like playing in some way or it's not proper maths" (Yr. 3); "college seems to like us to do a lot of practical activities looking at the National Curriculum and thinking up something whereas school, obviously they work from a scheme so it's practical with worksheets... but it's different to college" (Yr. 2)

\section{(2) Students fantasise/desire recipe knowledge rather than repertoire skills}

The pressure of school experience undoubtedly increases the desire for more 'telling': students wanted to hear "right, this is what you should be doing and this is how you should be teaching it" (Yr. 3) because "sometimes you think, if they are not going to tell you how are you going to learn" (Yr. 2). Many students gave examples of 'topic' or 'skill-based' knowledge which they felt college had not prepared them for: "in college... nobody will say to you how do you measure this table I only learnt that by being in school" (Yr. 2); "we've not done anything on time to teach the children very little subject application" (Yr. 4); "differentiation has never really been mentioned at all in maths. We have never actually said you have this range of abilities and you are going to have to do a completely different activity with them" (Yr. 1). One first year student, however, was already beginning to suspect that her fantasy of being given simple recipes would never be fulfilled: "I sometimes feel that we don't do as much on the topics we cover at primary school... but I don't know whether that's to come or whether that's for us to work out from what we have been taught" (Yr. 1).

(3) College maths is not targeted effectively to address practical teaching issues when needed

As mentioned earlier the structure of the BEd course at the time of the study was such that college mathematics sessions were effectively completed before the three major school experience placements were embarked upon. Some students felt let down by what they perceived as a lack of support: "for the last two years I've not had any maths input at all" (Yr. 4); "I've been let down this year because we've only had maths from September to January and then it finished... I'm here to learn I'm here to be a teacher and if I'm not good at maths I need help and they are just dropping it" (Yr. 2). One 4th year student, however, was beginning to understand the double-bind into which the theory/practice dilemma positioned him: "It had some kind of influence but some of it is a distant memory... it would have been useful to look at different types of assessment in core studies... but last year I wouldn't have understood as much about assessment" (Yr. 4).

\section{Mathematical experience on school placement}

(1) Mathematics becomes subsumed by the pragmatics of pedagogic concerns

Evidence indicated that for most students on school experience placement mathematics became completely subsumed by pedagogic concerns. Classroom management was a high priority: "I found it hard to keep the children on task throughout the lesson they were very excitable due to Mrs $\mathrm{H}$ not being here. I've had problems with classroom management whenever Mrs $\mathrm{H}$ isn't teaching... they just don't want to listen to me" (Yr. 2). Practical considerations such as the availability of equipment and space were very important: "we first started off doing tens and units and we did a number line we did it on the floor actually because it was quite a long number 
line" (Yr. 1); "they had cubes and they had to find combinations of 10 with the cubes but it was far too easy because they were just working them out in their heads they didn't need the cubes and they didn't want to use them so they were more of a hindrance really" (Yr. 3). The scheduling of mathematics lessons proved an unavoidable constraint. One student who was timetabled to have a 'topic' lesson once a week observed: "I do find it frustrating to come into a classroom and do 1 o' clock one day and then have a whole week in between and then the timetable says 'it's half past' but I can't do half past straight away [because they have forgotten $1 \mathrm{o}$ ' clock from the week before]" (Yr. 4). Language and differentiation were definite hurdles: "a lot of it was counting once we'd got over the English barrier" (Yr. 1); "it scares me a little bit actually to think that I've got to plan for all these different ranges of ability" (Yr. 1).

In a significant number of cases mathematics was conceptualised and spoken of through the language of the maths scheme "what would happen in the beginning because the teacher doesn't tend to differentiate, they're all on the same Heinemann book. And what she does do is there's another book the Peake book, and she uses that like an extension, so what she will do is move the higher ability ones on to the Peake books but she'll keep the lower ability ones on the Heinemann but they all do the same Heinemann" (Yr. 2). A few students were "just told to do scheme work" (Yr. 3) and many of their observations showed a critical awareness of "the scheme' and its pitfalls: "I think I wouldn't just use Heinemann I'd try and use lots of different sources" (Yr. 3); "I don't think they really understand the concept where money is concerned because it's another worksheet and they become almost like a Robot" (Yr. 2).

(2) School experience tutor and class teacher input is primarily pedagogic in nature

There was little evidence to indicate that student pre-occupation with pedagogic issues was shifted to focus on mathematics in discussion with the school experience supervisor: "my tutor didn't really contribute to maths things, everything was just general"; "[My tutor] was very supportive she'd say what organisation needed to be done" (Yr. 3). Tutors were perceived to have their own agenda: "she is interested in things like differentiation and integrated days. I am not sure I want to get into what integrated days are but that's her agenda" (Yr. 4); "it was quite good the maths he did watch - but then it was more on discussional skills" (Yr. 3); "she was more bothered about how I fit the class room how I respond to children. I've never had any specific maths feedback during school experience" (Yr. 4). One student took succour from the fact that her tutor also struggled with mathematics: "My school supervisor didn't like maths when he was in school he shared maths with another teacher... he never taught any maths. In a funny way it gave me confidence... because he was sharing his insecurities with me that made me feel better... He more gave me advice on management and organisation of class, how to motivate children... he never actually specified anything in maths" (Yr. 3).

School input was on occasions remarked upon: "I find that I've learnt mainly from going into the classroom from observing other teachers who were practising maths" (Yr. 4); "I got a little bit of explicit guidance on teaching a theme... [but] it was more organisational. As for my tutor I don't think he's seen me teach a maths lesson and if he had I'm sure he would talk about it explicitly" (Yr. 4).

Experience as a pupil in school informs the students' ideal model for teaching 
If a transitional meta-narrative can be identified in the stories of the students it is that their experience as a pupil informed their model for teaching. When reminiscences about their early mathematical experiences at the beginning of their first interview were compared to later responses regarding their attitude towards, and beliefs about, the teaching of mathematics it was clear that the former had had a profound effect upon the latter. A common line of argument was premised upon the value of empathy in the maths teachers' armoury: "I think I can sympathise more with them because I found it so difficult" (Yr. 1).

Most respondents seemed keen to correct the perceived failures of their own teachers: "I've realised that I can use my experiences to make sure that I don't teach maths in that way" (Yr. 3); "I feel I would have gained more by physical hands-on experience... which is what I try to do with the children. None could approach this teacher at all... she wasn't people friendly... I think you have got to be approachable for a start" (Yr. 4). Even the 1st year student who enjoyed maths at school found cause to criticise the technique of her teacher: "She would just sit at her projector and write it all down. We would just sit there it was pretty boring... [and later] I won't just sit behind my desk and say 'this is the question, give me an answer, work it out"' (Yr. 1). In many other cases the line of reasoning was clear:

Five pupils in our group were really good at maths and the teaching was mainly geared at these people... [and later] my main concern is putting the work at the right level for the children (Yr. 2).

I didn't enjoy it... [and later] I wouldn't want them to not enjoy a lesson... kids won't learn if it's not fun (Yr. 1).

I couldn't make the connections... [and later] They have to be able to feel there's a connection between what they are doing and later life, how maths can be used in other subjects (Yr. 3).

We'd tell him we were struggling, having difficulty... [and later] where they're struggling be patient try and understand where they're finding difficulty (Yr. 4).

One particularly poignant story came from a student whose parents had been told by one of his schoolteachers that he would "never be any good with his head he'll be very good with his hands and end up being a builder". In the event this was precisely what he did do for 10 years before embarking upon the BEd Course. The student later declared himself to be "very very wary of what I say to children.”

Whilst it was apparent that students' experiences as a pupils at school informed (most often in a negative sense) their ideal model of teaching; it appeared, in a significant number of cases, that this ideal model was modified by the pragmatics of classroom concerns. Thus the transmission narrative so often reviled in the student's own school experience resurfaced, albeit in a form, hybridised by the intervention of other narratives.

\section{Contextual parameters in the discursive framing of mathematics}


In the presentation of our empirical results we have shown how students report on the affective or perceptual aspects of mathematics and its teaching and how this moves to a formatting of the structural space they inhabit. We now seek to discuss briefly some of the data from an alternative perspective; namely the way in which student perceptions are shaped by the contextual parameters in which they work. We suggest that these contextual parameters are instrumental in the ways in which the students discursively constitute mathematics. In this section we seek to identify some of these structural constraints and show how they shape the students' perceptions of this task. For example, hitherto we have spoken only of the students' perception of their training course. Here we will offer a brief account of how course tutors visualise their own actions and how they, in turn, are interpreted by students. We attempt to provide an account of the structural frame within which this occurs and show how it shapes students' perceptions of the teaching task. These two alternative perspectives might be seen as complementary hermeneutic arcs (Ricoeur, 1981, 209-221). The first, from perception to structure, reveals how student perceptions frame the space they are working in; and the second, from structure to perception, shows how contextual parameters shape student perceptions. It is this form of hermeneutic duality that will inform the analysis we shall offer shortly.

In their journey from school learner to schoolteacher students are influenced by numerous structures which shape the way in which they begin to see mathematics and its teaching. These structures were assumed and explicitly addressed in our questioning of the students regarding the National Curriculum, the school mathematics policy and the influence of class teachers and college tutors during school placements. Inevitably there is some interaction between the assumptions we made in creating our research design (the structural framework those assumptions presuppose), the questions we posed in respect of it, and the interpretations we made of the student responses. Here we sketch some of the structural components that seem to be operating at each stage and how these impact on and shape students' perceptions of mathematics and its teaching. We shall take each of the three phases identified in turn:

\section{i) Student experience as a pupil in school}

Student accounts of their own schooling seem to bear out a traditional image in which the teacher adopts a transmission style of teaching, covering the curriculum with view towards the day of judgement when the pupils sit for public examinations. In this context the student reports their experience of being a pupil as being characterised by pressure to complete given tasks where feelings of right or wrong predominate. The teacher, governed by examination concerns or by a didactic understanding of teaching, creates a version of mathematics dominated by concern for correct answers which pupils experience as pressure to get it right or failure in getting it wrong.

We were taught either from the blackboard or out of books... I didn't understand it and I didn't have anybody that I felt I could go up to and say "I don't understand, can you show me again".

\section{ii) College sessions on the teaching of mathematics}

The students involved in the study span a period of rapid evolution in BEd course structure as government guidelines were anticipated and implemented (e.g. DfEE Circular 10/97, 
Consultation on the Initial Teacher Training National Curriculum, 1997). The fourth year students interviewed would have experienced a rather different first year to their present day contemporaries. A tutor perspective describing the course at the time the 4th years were beginning their training was recorded by Hanley and Brown, (1996):

The central purpose of the course is to enable student teachers to engage in a dialectic between their proposed intentions, their actions, and their reflections on both of these, in writing and in discussion with peers and tutors. For this reason work on "the disciplines", as present in many older-style initial training courses, is replaced by greater attention to individuals building their 'practical knowledge'.

In the early stages of the mathematics strand students work on their own learning of mathematics as a vehicle through which they become aware of possible issues relating to children's learning. Understandings developed in this way are then checked out in school placements. Implications for their own practice are then explored, in the first instance, with small groups of children and then in limited tasks with a whole class. Eventually this leads to the student taking responsibility for the programme of work for a whole class for an extended period. The assessment of the students rests largely on their skill in representing and justifying their intentions and achievements, both verbally and in writing. The central item in the assessment of the final school placement is a written file through which students monitor changes and development in their practice with view to controlling both. (Hanley and Brown, 1996)

Whilst many of these aspirations remain in place, as a result of recent developments (DfEE, 1997, 1998) college tutors have become increasingly responsive to specific government requirements. Within this new frame students have sessions which are designed to meet these requirements and those of the forthcoming 'numeracy hour', in particular, students are required to undertake personal subject area and pedagogical 'audits'. These changes have forced a more explicit reconciliation by tutors of the alternative descriptions of mathematics (e.g. phenomenological or official) and thus a tighter association between 'pedagogic content knowledge' and substantive knowledge of mathematics. For fourth year students in the study cohort these changes have only had limited impact whilst for first years the changes have been more significant. Seemingly, the data suggests that all students expected an extension of the discomfort of their own school experience and were relieved to find that these pressures were absent from college training.

In one college session observed, for example, approaches to subtraction were compared and contrasted towards clarifying numeric strategies. Whilst the students reported school experience of this mathematical area as being about getting answers correct, in the college session the emphasis was on different ways of seeing the process and discussing the relative merits.

I've now learnt it's not a case of, it doesn't matter if you don't get the answer as long as you can understand the processes and eventually you will come to the answer but not that same sort of pressure. (Yr. 2) 
It's easy here ... it's fun again now, even though we're nearly at our level, it's relating it to teaching it to children (Yr. 2)

Assessment of the students did not feature as part of the session and was generally adjourned until the end of year assignment. National Curriculum and other official frames were offered for critical evaluation. The modes of assessment within the course emphasised reflective ability and analysis as well as demonstrating a factual knowledge of the curriculum and its content.

\section{iii) Students on later school placements}

During later school placements college sessions addressing issues of mathematics were generally in the distant past but they were remembered as having provided a positive image of mathematics. The students no longer seemed anxious about the subject per se. Similarly for college supervisor and class teacher mathematical concerns were in the background to a more general discourse of pedagogy and organisation: "To my supervisor it was just whether I could control the class or not" (Yr. 3).

Mathematics was often little more than following a scheme or conducting some simple practical activity that concealed little more than practice of existing skills. The students' conception of the mathematical topic was often fairly narrow with teachers providing the content area to be covered sometimes without clear definition of its location within the National Curriculum or even in the schools own maths policy.

Because the teacher wanted certain things doing, it was just addition in the first you had one lesson to teach them addition of money and one lesson to teach them subtraction so you didn't really get time to explore a lot (Yr. 3)

This model seemed not to conflict with the positive image provided to the students in college but this did not necessarily mean that the pupils in their classes did not experience similar difficulties to the student teacher's own school experience. One student, when interviewed, professed herself to be keen to avoid her pupils suffering a similarly bad experience to her own. Yet our lesson observation showed her leaving many children to get on with work on their own; her only interaction with them related to the correctness, or more often the non-correctness, of their work.

\section{Theoretical structuring of findings}

Our task now is to offer a theoretical frame within which our findings might be contextualised. We begin by un-picking how the alternative influences on students' conceptions of mathematics are predicated on a variety of assumptions as to the nature of mathematics and the associated forms of accountability these suggest. In particular, in developing our discussion, we encountered three dualities arising from what appear to be alternative constructions of mathematics, the teaching of it and the perspective we assume in describing this teaching.

Duality One - phenomenological/ official versions of mathematics 
what you see as opposed to what you are meant to see

resolution in recognising that both are oriented around the same social entities

Duality Two - discovery/ transmission conceptions of mathematics teaching

what you find as opposed to what you are given

resolution in seeing each in the other

Duality Three - perceptual/ structural conceptions of mathematics teacher's task

insider account as opposed to the framing which hosts this account

resolution in recognising that they are mutually constitutive

The dualities, each of which are potentially dichotomous, comprise a first item rooted in the individual insider's perspective and a second item implying a socially constructed overview. In each case, the first item is spoken of in qualitative terms, whilst the second requires a more quantitative or structural style of analysis. Addressing this issue of dichotomies Hilton as quoted in Steiner (1987, p. 11) suggests:

Many of the prevailing dichotomies are false, that is to say that the two concepts which are set in opposition to each other do not form part of an either/or situation; that while the two concepts under scrutiny are different, they have an essential overlap, and that, when properly understood and applied, their can in fact mutually reinforce each other.

We also propose that for each duality we can resolve possible dichotomies by highlighting how the first item can be seen in the second and vice versa.

\section{Duality One - phenomenological/official versions of mathematics}

Alternative views of mathematics are dependent on where their proponents are positioned in any educative process. For a tutor charged with the initial or in-service training of teachers, qualitative concerns are clearly of importance. There is a need to equip one's students with particular mathematical insights, to prioritise a positive attitude to the subject, to value personal understandings and to develop these. Meanwhile, a policy maker promoting effective performance in public examinations or tests to be used in international comparison is likely to be motivated differently. Here perhaps formats of learning and assessment rather than more personal notions of mathematical understanding underpin the hard currency required to make such quantitative comparisons possible. And so the emphasis is on the pupil being required to describe particular mathematical ideas in an acceptable language and to filter any personal insights 
through this language. The teacher in school is increasingly governed by such concerns and pressures to change have been manifest in the recent policy initiatives outlined earlier.

The affective experience of student teachers has been widely researched, as mentioned earlier. In this study we confirmed that there were widespread anxieties among our target group concerning their own learning of mathematics during their own schooling and of the prospect of teaching the subject themselves. It seemed the approach to mathematics taken within college training addresses these concerns by offering a view of mathematics which values the learner's own point of view and emphasises mathematics at primary level rather than the student's own level. As such mathematics is seen primarily as a learning experience centred on the learner rather being defined by external criteria. This mirrors a widespread view among educators as to how the learning of children might best be seen, where the quality experience of the children in learning mathematics is perhaps privileged over objectives defined in terms of mathematical content. Within such a view of mathematics there is an emphasis on mathematical processes and application. This however does not provide a comprehensive picture of the style of mathematics faced by student teachers when they return as teachers to a school based environment. Here they encounter again mathematics not unlike that which they faced in school as pupils. Not only the style of learning but also the style of regulation move away from the learner centred focus encountered in college. This version of mathematics is predicated on rather different aspects of the mathematics. Here cognitive ability is understood more in terms of performance of prescribed procedures. We suggest that these two aspects of mathematics display a certain amount of incommensurability but nevertheless coalesce under the same heading of "mathematics".

Mathematics 1 (phenomenological perspective)

In this perspective emphasis is placed on the student exploring mathematics, making connections, seeing structure and pattern. The teacher's task is understood more in terms of facilitating learning from the learner's current perspective rather than didactic teaching. Such an approach, which is often seen as being more 'child centred' or 'discovery' oriented, emphasises process and the 'using and applying' of mathematics, but a mathematics that is understood fairly broadly. Assessment is often targeted at the student's attempts at articulating their perspective. As an example of teaching strategy electronic calculators are seen as an effective aid for developing numeracy since they encourage mental calculation in place of mechanical and tedious pencil and paper methods employing poorly understood algorithmic procedures.

This sort of perspective reveals itself within the students' accounts where they are discussing their own teaching:

Trying to understand where the children are coming from and where they got their ideas to start with (Yr. 3)

...if you're trying to teach somebody else and you can't tell them the best way, you've got to help them find it for themselves and then build on that, so you've got a responsibility to guide and help, not work it out for yourself and dictate how it's done. (Yr. 4)

(This lesson) allowed me to see what type of level they were up to, independent of the scheme, if they are just working with themselves with numbers, and it 
also allowed me to see how they developed in their thinking, how they were working things out here. (Yr. 4)

Mathematics 2 (official perspective):

In this perspective mathematical achievement is understood more in terms of performance of prescribed mathematical procedures. This is quantifiable through diagnostic testing and broader understanding is anchored around test indicators in a statistically defined environment. Mathematics itself is understood as being describable as a list of mathematical content topics, and thus a transmission approach may be favoured. The teacher's task is to initiate students into these conventional procedures perhaps by demonstrating them and assisting children while they are practised. Proponents of such a view of mathematics are often opposed to calculator use since they perform the very procedures featured on the preferred forms of diagnostic test.

This sort of perspective reveals itself more obliquely in the students' accounts primarily through the way in which they hint at their anchorage in transmission methods, where the teacher's task is seen as being to get the idea across, albeit approaches that seek to soften the negative aspects of transmission experienced by them as pupils in school:

I think you have to go back to the basics to get it across to people. (Yr. 1)

...when you're a teacher you have to be able to explain it for somebody else to understand it. I can't get my message across - explanation again. (Yr. 1)

I think you have got to be very clear in your explanations and I think subjects do need explanations before you give out the books. (Yr. 2)

...so I started by putting the easy questions because if you start with the harder ones they will just give up straight away. I started through till the subtraction at the end so that I knew that the higher group would be able to get on to that quicker than the others. (Yr. 3)

The two sorts of mathematics are governed by different sorts of criteria; the phenomenological focuses on the learner's experience the official on the production of predefined and quantifiable mathematical output. To develop this point further it may be helpful to offer an another example. In his analysis of the SMP teaching scheme Dowling (1996) found mathematics designed for less able students to be of a very different nature to that given to their more able peers. For any given topic, the emphases in the instruction varied according to the supposed ability of the student. This seemed to result in exclusion for the less able from the real business of mathematics, as understood in more abstract terms. They were caught in the discourse of "less able" mathematics. The analysis identified at least two styles of mathematics, each characterised by a discourse with associated styles of illustration, questioning etc. Clearly there are many such discourses operating in mathematics education. Differences between these discourses are often swept over as a consequence of outcomes being seen primarily on a register of mathematical content, independent of the processes that lead to these. Each of these discourses is predicated on some sort of mathematical objective whether this be tied down to performance in a specific discursive frame such as the solving of a linear equation or more transcendental 
mathematical claims such as abstraction, the noting of generality or intuition. The stressing of certain features results in an assertion of a particular view of mathematics as though this can be specified independently of broader learning objectives, such as developing intuition or doing well on a diagnostic test featuring linear equations (cf. Brown et al, 1998).

When mathematical ideas are invested with an even more explicit pedagogical dimension as in the mathematical training of would be teachers this diversity in illustrative framings is accentuated yet further. We get caught in what appears to be an irreconcilable conflict between nurturing personal experience and utilising measuring devices. This conflict we suggest can be softened by recognising that both perspectives are oriented around the same shared social phenomena. The individual cannot claim a wholly personal perspective; the space s/he occupies and the mathematics being studied cannot be observed except through socially derived filters. Personal insights are relatively meaningless unless they can be attached to shared forms of expression. Meanwhile criterion-referenced metrics are meaningless and dysfunctional unless they are derived from careful examination of normative practices (cf. Habermas, 1997). The implications this has for teaching are discussed next.

\section{Duality Two - discovery/ transmission conceptions of mathematics teaching}

The potential dichotomy between phenomenological and official versions of mathematics is to some extent mirrored in these supposed alternative teaching orientations. The choice between discovery and transmission appears as an apparent conflict between valuing what children do see and measuring what they should see. It is interesting that these perspectives have become polarised in so many debates (e.g. on the use of the calculator, on the importance of Using and Applying Mathematics (e.g. Simon et al, op cit.)) and in others attempts have been to efface this polarisation. Askew et al. (1997), for example, seem to dichotomise what we are calling Mathematics 1 and 2 as being associated respectively with 'discovery' (learner perspective prioritised) and 'transmission' (teacher/ official perspective prioritised) styles of teaching and offer 'connectionism' as a reconciliation of the two perspectives. The feature of connectionism we would highlight in particular is its suggestion that teachers draw links between alternative perspectives as offered by children and discuss how these "connect" with the curriculum topics being addressed. Personal insights are sought but of shared phenomena, a sharing that takes place and develops during lesson time with children and teacher working together. Mathematical meanings are socially constructed at the level of classroom activity through attempts at achieving shared understanding of ideas derived from curriculum topics (cf. Cobb, 1998). It is this sort of reconciliation that motivates our work here in suggesting possible theoretical frames for combining apparently incommensurable perspectives.

Students in the sample revealed harrowing memories of being recipients of transmission styles of mathematics teaching in schools, yet their capacity to radically reconceptualise mathematics and its teaching seemed limited to enacting a pseudo-transmission style where the approach was laced with motivational niceties. They thus attempt reconciliation but seem to lack the capacity to combine the two dichotomised styles. Askew et al are associating this capacity with "effective" experienced teachers. For many in our sample of non-specialist students this seemed to be out of reach in both conception and practice. 
No discussion, it's not related to anything, you just thought what's the point in this?... You need to be able to put maths into a way that is relevant to children.. so that they are involved in it (Yr. 2)

I can never understand why it was done in that way and what it was for... when I teach maths I have to make sure number one that I understand completely what I am doing in order to put it over to the children to get them to understand why they are doing it first and then what they are doing (Yr. 3)

\section{Duality Three - perceptual/structural understandings of mathematics teacher's task}

In presenting our account of the three phases student teachers pass through in making the transition from learner of mathematics to teacher of mathematics we offered two perspectives on how conceptions of mathematics emerge in students' minds. Firstly, we focused on how students' report on the affective or perceptual aspects of mathematics and its teaching and how this account formats the structural space they inhabit. Secondly, we provided an account of the structural frame within which this occurs and how this shapes perceptions of the teaching task. We have suggested that these might be seen as two complementary hermeneutic arcs; from perception to structure and from structure to perception.

In carrying out empirical research in the teaching of mathematics there has been a tendency for work to gravitate to one or other of two perspectives (Macleod, 1992). The first of these comprises work based around individuals' perception of their situation discussed in qualitative terms, whether these individuals be children learning mathematics (e.g. anxiety about mathematics) or teachers engaged in teaching mathematics (e.g. teacher beliefs or the phenomenological strand of studies outlined earlier). The second perspective concerns work focusing on measurable achievements of such individuals or the structure within which they are working (as exemplified in the official documents outlined in the introduction and in the discussion of contextual parameters facing college tutors). Macleod (1992, p. 590), for example, asserts a dichotomy between cognitive and affective styles of research He has suggested research in affective issues of mathematics education, the insider's perspective, is fairly extensive but rather weakly connected to work on focusing on the outsider's analysis of that insider (cf Mason, 1994). In reflecting on their own experience of mathematics the students in our study generally seemed unable to articulate their understanding of the subject except in affective terms. Prior to ITE maths was generally conceptualised as a bad school experience. For those later on in the course the cognitive dimensions of mathematics are subsumed within the social practices of teaching as perceived within the broader primary education space. However, recent theoretical work in mathematics education research has questioned notions of individual cognition (Ernest, 1997; Brown, 1997). Whilst we agree with Macleod that research on the affectivity of learning mathematics is under theorised the problem will not be addressed by connecting this to theoretical work centred on cognition unless it is recognised that cognitive issues in mathematics are a function of the social environment and how it evaluates itself. For example, at different times mathematics is shaped through the filter of diagnostic testing and by the control principles of classroom organisation. Similarly, it seems that very often affective or perceptual concerns dominate the training discourse while structural accounts dominate the discourse of policy. Resolution of these alternative perspectives requires a softening of each within the life of the 
perspective of the individual concerned, towards demonstrating how the individual understands mathematics as generated through social activity and regulated through socially defined parameters.

\section{Conclusion}

In having gravitated within this study to question how mathematics was conceptualised by nonspecialist primary teacher trainees, we found evidence to suggest that this was a function of the stage students had reached in their training. In moving to a clearer sense of how such students conceptualise mathematics and its teaching, however, we became aware that differences between alternative conceptions of mathematics are overlooked in the broader public domain. That is, we located an incommensurability between the ways in which mathematics is presented in many official documents and the way in which it is often depicted during college training and in certain curriculum documents. Thus the students' perception can be seen as emphasising adherence to these alternative conceptions as they encounter changing demands, whether this be learning mathematics to pass an exam in school, appreciating the learning task as a student in college, or fitting in to conventional school practices when on a school placement.

We have proposed an approach to combining these alternative conceptions of mathematics in a more complementary relation. This recognises that mathematics is constructed according to specific cultural, mathematical, pedagogical and political agendas and that identification of its features is a function of these diverse concerns. We also assume that the students' conceptions of mathematics need to be responsive to these alternative pressures; certain difficulties have been encountered because the dichotomy between 'Mathematics 1' and 'Mathematics 2' has been over pronounced. Proponents of 'Mathematics 1' have often emphasised conceptions of a custom built version of mathematics governed by supposedly more pure notions of what constitutes mathematics. For example materials produced by the Association of Teachers of Mathematics during the eighties featured investigations in non-standard mathematical topics. We propose, in line with current practice on the course described, that a conception of mathematics can be constructed, which is more harmonious alongside the more traditional conceptions of mathematical topics, but without the associated assumption that this implies a particular pedagogical attitude to these topics. It is possible to have a 'Mathematics 1' attitude attached to a 'Mathematics 2' style selection of topics. By employing a hermeneutic approach we suggest the divide between alternative conceptions of mathematics can be effaced by emphasising the circularity of moving between hard edged results and interpretations of them. That is, between the numerical results of diagnostic tests and the individual's socially conditioned cognitive space which hosts them. Such a resolution seeks to encompass changes in belief, attitude, influence, affect and role from the perspective of the student teacher. 'Connectionism', as offered by Askew et al. (1997), addresses this in its insistence on valuing alternative individual perceptions of key core ideas. Such an approach seems a promising direction for mathematical studies within ITE courses, although our results seem to suggest that such an approach might be beyond the current intellectual and performative capacity of many non-specialist students. 
We have also pointed to a reported difficulty in mathematics education research in harmonising perceptual and structural conceptions in the learning of mathematics and in the training of future teachers of mathematics. For this potential dichotomy, which is actualised in many discussions and policy decisions, we have offered another hermeneutic resolution. Here perceptual and structural are situated in the same frame through seeing them as subsumed within a broader social construction. This echoes recent theoretical work in mathematics education research that castigates notions of the individual. Within ITE this could include a more critical focus on how demands teachers need to address in their individual practice are associated with the interests of the various stakeholders. We have argued that the social situation of mathematics needs to be recognised and that individual perceptions of mathematics cannot divorce themselves from the social frames in which mathematics is generated and understood by others. But conversely policy makers cannot assume custody of the right to decide how this social framing is constructed since this requires a more sophisticated account of the normative practices through which mathematics comes into being. A key policy implication for ITE courses that might be suggested in the light of this recognition is that many of the features prominent in such courses which have fostered a more positive attitude to mathematics should be retained but that such approaches should be more specifically targeted at accommodating (both critically and compliantly) the social filters (such as curriculum documents and associated classroom practices) through which mathematics is increasingly being understood. It also seems clear that mathematics as a discipline within primary schools has some need of asserting its own identity amidst a busy ITE schedule often controlled by those with a broader agenda. In particular, there does seem to be a need to ensure that school based work features specific attention to mathematics and other subject areas if these are to rise above the surface of an overly organisational concept of primary practice. This seems essential if mathematics is to be generated rather than merely administered in the classroom. 


\section{Acknowledgements}

This paper reports on the Primary Student Teacher's Understanding of Mathematics and its Teaching project funded by the Economic and Social Research Council, project number R000222409. The research team would like to express its gratitude for this support.

\section{REFERENCES}

ALEXANDER, R., ROSE, J., \& WOODHEAD, C. (1992) Curriculum Organisation and Classroom Practice in Primary Schools, London: Department of Education and Science.

ASKEW, M., BROWN, M., RHODES, V., JOHNSON, D \& WILIAM, D. (1997) Effective Teachers of Numeracy (London, Kings College).

AUBREY, C. (1993) An investigation of the mathematical knowledge and competencies which young children bring into school. British Educational Research Journal, 19, pp. 19-37.

AUBREY, C. (1994) An investigation of children's knowledge of mathematics at school entry and the knowledge their teachers hold about teaching and learning mathematics, about young learners and mathematical subject knowledge. British Educational Research Journal, 20, pp. 105-120.

AUBREY, C. (1995) Teacher and pupil interaction and the process of mathematics in four reception classrooms. British Educational Research Journal, 21, pp. 31-48.

AUBREY, C. (1996) An investigation of teacher's mathematical subject knowledge and the processes of instruction in reception classes. British Educational Research Journal, 22, pp. 181-197.

APPLEGATE, J. (1985/7) Early field experiences. Recurring dilemmas. Journal of Teacher Education, 36 (2).

BALL, D. (1988) Unlearning to teach mathematics. For the Learning of Mathematics, 8 (1), pp. 40-48.

BALL, D. (1990) The mathematical understandings that prospective teachers bring to teacher education. The Elementary School Journal, 90 (4), pp. 449-466.

BALL, D. (1991) Research on teaching mathematics: making subject-matter knowledge part of the equation. Advances in Research on Teaching, 2, pp. 1-48.

BERLINER, D. (1988) Implications of Studies of expertise in pedagogy for teacher education and evaluation. In The Educational Testing Service (Ed.), New Directions for Teacher Assessment, Proceedings of the 1988 ETS Invitational Conference, Princetown, New Jersey.

BIRD, T., ANDERSON, SULLIVAN \& A. SWIDLER (1993) Pedagogical balancing acts: attempts to influence prospective teachers' beliefs. Teaching and Teacher Education, 9 (3), pp. 253-268

BOYDELL, D. (1994) Relationships and feeling: the affective dimension to mentoring in the primary school' Mentoring and Tutoring, 2 (2), pp. 37-44

BRAMALD, R., HARDMAN, F. \& LEAT D. (1995) Initial teacher trainees and their views of teaching and learning. Teaching and Teacher Education, 11 (1), pp. 23-32

BROWN, S., COONEY, T. \& JONES, D. (1990) Mathematics teacher education. In W. Houston (Ed.), Handbook of Research on Teacher Education, (London, Macmillan), pp. 639-656.

BROWN, T. (1997) Mathematics Education and Language: interpreting hermeneutics and post-structuralism (Dordrecht, The Netherlands, Kluwer)

BROWN, T., EADE, F \& WILSON, D. (1998) Researching transition in mathematical learning, Proceedings of the twenty second conference of the international group on the Psychology of Mathematics Education, University of Stellenbosch, South Africa, 1998.

CALDERHEAD, J. \& ROBSON, M. (1991) Images of teaching: student teachers' early conceptions of classroom practice. Teaching and Teacher Education, 7 (1), pp. 1-8

C.A.T.E. (1992) The Accreditation of Initial Teacher Training under Circulars 9/92 and 35/92

CARRE, C. \& ERNEST, P. (1993) Performance in subject matter knowledge in mathematics. In N. BENNETT \& C. CARRE (Eds) Learning to Teach (London, Routledge). pp. 36-50

CARTER, D. CARRE, C. BENNETT, S. (1993) Student teachers' changing perceptions of their subject matter competence during an initial teacher training programme, Educational Researcher, 35 (1) pp. 89-95. 
CARTER, K. (1990) Teachers' knowledge and learning to teach. In W.R. HOUSTON (Ed.) Handbook of Research on Teacher Education (London, Macmillan) pp. 291-310.

COBB, P. (1994) 'Where is the mind? Constructivist and socio-cultural perspectives on mathematical development', Educational Researcher, 23 (7), pp. 13-19.

COBB, P. (1998) Analysing the mathematical learning of the classroom community: the case of statistical data analysis. Plenary address at the twenty second conference of the international group on the Psychology of Mathematics Education, University of Stellenbosch South Africa.

DES (1988) The New Teacher in School: A survey by HM Inspectors in England and Wales. London: HMSO

DfEE (1997). Circular 10/97 Teaching: High Status, High Standards. Requirements for courses of Initial Teacher Training H.M.S.O.

DfEE (1998) Teaching: High Status High standards Circular 4/98, H.M.S.O.

DES (1983) Teaching Quality. HMSO, London.

DOWLING, P. (1996) A sociological analysis of school mathematics texts, Educational Studies in Mathematics, 31, pp. 389-415.

ELLIOTT, B. \& CALDERHEAD, J. (1993) Mentoring for teacher development: Possibilities and caveats' In D. MCINTYRE, H. HAGGER \& M. WILKIN (Eds.) Mentoring: Perspectives on School-Based Teacher Education, (London, Kogan Page), pp. 166-189.

EDWARDS, A. (1995) Teacher education: partnership in pedagogy?, Teaching \& Teacher Education, 11 (6) pp. 595-610

EISENHART, M. BEHM, L. \& ROMAGNANO, L. (1991) Learning to teach: developing expertise or rite of passage?, Journal of Education for Teaching, 17 (1), pp. 51-69.

GLASER, B. (1978) Theoretical Sensibility, Sociology Press, Mill Valley, CA.

GRIFFITHS, M. \& TANN, S. (1992) Using reflective practice to link personal and public theories, Journal of Education for Teaching, 18 (1).

GROSSMAN, P., WILSON, S., \& SHULMAN, L. (1989) Teachers of substance: subject matter knowledge for Teaching'. In M.C. REYNOLDS (Ed.) Knowledge Base for the Beginning Teacher (Oxford, Pergamon Press). pp. 23-32.

GUILLAUME, A. \& RUDNEY, G. (1993) Student teachers' growth towards independence: An analysis of their changing concerns, Teaching and Teacher Education, 9 (1) pp. 65-80.

HABERMAS, J. (1997) Between Facts and Norms (Cambridge, Polity)

HANLEY, U \& BROWN, T (1996) Building a professional discourse for mathematics in intial teacher education, Research in Education, 55, pp. 39-48.

HILTON, P. (1977) Education in Mathematics and Science Today: The Spread of False Dichotomies. The Proceedings of the 3rd International Congress of Mathematics Education, pp. 75-97. Karksruhe.

HOLLINGSWORTH, S. (1988) Making field-based programs work: a three level approach to reading education, Journal of Teacher Education, 39 (4), pp. 224-50.

H.M.I. (1991) The Professional Training of Primary School Teachers. (London, HMSO).

JAWORSKI, B. \& WATSON, A. (1994) Mentoring in Mathematics Teaching (London, Falmer Press).

KYRIACOU, C. (1993) Research on the Development of Expertise in Classroom Teaching During Initial Training and the First Year of Teaching, Education Review, 45 (1), pp..

LAMPERT, M. (1988) What can research on teacher education tell us about improving quality in mathematics education, Teaching and Teacher Education, 4, pp. 157-170.

LAVE, J. \& WENGER, E. (1991) Situated Learning: Legitimate, Peripheral Participation. (Cambridge, Cambridge University Press).

LERMAN, S. (1986) Alternative Views of the nature of mathematics and their possible influence on the teaching of mathematics. Unpublished PhD dissertation. King's College London.

LERMAN, S. (1990) Alternative perspectives of the nature of mathematics and their influence on the teaching of mathematics, British Educational Research Journal, 16 (1), pp . 53-61.

LINCOLN, Y. \& GUBA, E. (1985) Naturalistic Enquiry, (London, Sage)

LORTIE, D. (1975) School Teacher. (Chicago, University of Chicago Press).

MAYNARD, T. \& FURLONG, J. (1993) 'Learning to teach and models of mentoring'. In D. MCINTYRE, H. HAGGER \& M. WILKIN (Eds.) Mentoring: Perspectives on School-Based Teacher Education (London, Kogan Page). pp. 69-85. 
MCDIARMID, G., BALL, D., \& ANDERSON, C. (1989) Why staying one chapter ahead doesn't really work: subject-specific pedagogy. In M.C. REYNOLDS (Ed.) Knowledge Base for the Beginning Teacher, (Oxford, Pergamon Press) pp. 193-204

MCLEOD, D. (1992) Research on affect in mathematics education: a reconceptualisation, in D. GROUWS (Ed.) Handbook of Research on Mathematics Teaching and Learning (New York, Kogan Page).

MCNALLY, J., COPE, P., INGLIS, B., \& STRONACH, I. (1994) Current realities in the student teaching experience: a preliminary enquiry, Teaching and Teacher Education, 10 (2), pp..

MCNAMARA, D. (1990) Research on teachers' thinking: its contribution to educating student-teachers to think critically' Journal of Education for teaching, 16 (2), pp. 147-60.

MCNAMARA, D. (1991) Subject knowledge and its application: problems and possibilities for teacher educators, Journal of Education for teaching, 17 (2), pp. 113-128.

MASON, J. (1994) Researching from the inside in mathematics education: locating an I-you relationship. Proceedings of twentieth conference of the international group on the Psychology of Mathemaitcs Eeducation, University of Lisbon (1), pp. 176-191.

MEREDITH, A. (1993) Knowledge for teaching mathematics: some student teachers' views, Journal of Education for Teaching, 19 (3), pp. 325-338.

MEREDITH, A. (1995) Terry's learning: some limitations of Shulman's pedagogical content knowledge, Cambridge Journal of Education, 25 (2), pp. 175-187.

MILES, M. \& HUBERMAN, A. (1984) Qualitative Data Analysis (Beverley Hills, CA, Sage Publications).

MORGAN, C. (1997) Generic ex[pectations and teacher assessment. Paper presented to the group on the Research intoSocial Perspectives of Mathematics Education, Institute of Education.

MORGAN, J. (1977) The Affective Consequences for the Learning and Teaching of Mathematics of an Individualised Learning Programme (Stirling, University of Stirling).

PETERSON, P., FENNEMA, E., CARPENTER, P. \& LOEF, M. (1989) Teachers' pedagogical content beliefs in mathematics, Cognition and Instruction, 6 (1), pp. 1-40.

REYNOLDS, D. \& FARRELL, (1996) Worlds Apart, (London, OFSTED).

RICOEUR, P. (1981) Hermeneutics and the Human Sciences, (Cambridge, Cambridge University Press)

SHULMAN, L. (1987) Knowledge and teaching: foundations of the new reform, Harvard Educational Review, 57 (1), pp. 1-22.

SHULMAN, L. (1986) Those who understand: knowledge growth in teaching, Educational Researcher, 15 (2), pp. 4-14.

S.I.M.S. (1990) Second International Mathematics Study.

SIMON, S. \& BROWN, M. (1996) Teacher beliefs and practices in primary mathematics. Paper presented at the 20th Conference of the International Group for the Psychology of Mathematics Education. Valencia, Spain.

STEINER, H. (1987) Philosophical and Epistemological Aspects of Mathematics and their Interaction with Theory and Practice in Mathematics Education. For the Learning of Mathematics 7 (1), pp. 7-13.

STONES, E. (1992) Quality Teaching: a sample of cases (London, Routledge).

STRONACH, I. \& MACLURE, M. (1997) Educational Research Undone: the postmodern embrace, (Buckingham, Open University Press).

STRAUSS, S. (1993) Teachers pedagogical content knowledge about children's minds and learning - implications for teacher-education, Educational Psychologist, 28 (3), pp. 279-290

SU, J. (1992) Sources of influence in preservice teacher socialization, Journal of Education for Teaching, 18 (3), pp. 239-258.

TABACHNICK, B. \& ZEICHNER, K. (1986) Teacher beliefs and classroom behaviours: some teacher responses to inconsistency. In M. BEN-PERETZ, R. BROMME \& R. HALKES (Eds.), Advances of Research on Teacher Thinking, Lisse, Swets and Zeitlinger.

THOMPSON, A. (1984) The relationship of teachers' conceptions of mathematics and mathematics teaching to instructional practice, Educational Studies in Mathematics, 15, pp. 105-127

TICKLE, L. (1994) The Induction of New Teachers: Reflective Professional Practice. (London, Cassell).

T.I.M.M.S. (HARRIS et al) (1996) Third International Mathematics and Science Study.

VONK, J. (1993) Mentoring beginning Teachers: mentor knowledge and skills, Mentoring, 1, pp. 31-41

WHITE, J. (1989) Student Teaching as rite of Passage, Anthropology and Educational Quarterly, 20, pp. 177-195.

WRAGG, E., BENNETT, S., \& CARRE C. (1989) Primary teachers and the National Curriculum, Research Papers in Education, 4 (3), pp. 17-45. 
